\title{
A curiosa história da primeira escola a formar um agrimensor no Estado de Santa Catarina
}

The curious history of the first school to train a surveyor in the State of Santa Catarina

La curiosa historia de la primera escuela en formar a un agrimensor en el Estado de Santa Catarina

\author{
Cesar Rogério Cabral \\ Instituto Federal de Santa Catarina (Brasil) \\ https://orcid.org/0000-0003-4170-4410 \\ http://lattes.cnpq.br/5017586133450806 \\ ccabral@,ifsc.edu.br \\ Julia Cucco Dalri \\ Universidade do Estado de Santa Catarina (Brasil) \\ https://orcid.org/0000-0003-4237-8880 \\ http://lattes.cnpq.br/9072707757899689 \\ juliacucco@yahoo.com.br \\ Markus Hasenack \\ Instituto Federal de Santa Catarina (Brasil) \\ https://orcid.org/0000-0003-4477-9143 \\ http://lattes.cnpq.br/4175654545239374 \\ hasenack@ifsc.edu.br
}

\section{Resumo}

A história da formação de agrimensores em Santa Catarina e por extensão no Brasil está dispersa em vários arquivos de instituições públicas e privadas, sendo que uma parte significativa está definitivamente perdida. Em Santa Catarina, os agrimensores registrados vinham de escolas de outros estados ou com diplomas validados de outros países, condição que dificulta o resgate de documentação que aponte o primeiro profissional formado em Santa Catarina. As pesquisas indicam que em 1901 surgiu em Florianópolis o Instituto Technico Commercial e Naval, escola com esta finalidade em Santa Catarina, estabelecendo-se a partir desta, outras instituições que então passaram a formar Agrimensores no Estado.

Palavras-Chave: Instituto Technico Commercial e Naval. Agrimensura. Frederico Selva. 


\begin{abstract}
The history of the training of surveyors in Santa Catarina and by extension in Brazil is dispersed in several archives of public and private institutions, a significant part of which is definitely lost. In Santa Catarina, registered surveyors came from schools in other states or with validated diplomas from other countries, a condition that makes it difficult to retrieve documentation that points to the first professional trained in Santa Catarina. Research indicates that in 1901, the Instituto Technico Commercial e Naval emerged in Florianópolis, a school with this purpose in Santa Catarina, establishing itself from there, other institutions that then started to form Surveyors in the State.
\end{abstract}

Keywords: Instituto Technico Commercial e Naval. Land surveying. Frederico Selva.

\title{
Resumen
}

La historia de la formación de agrimensores en Santa Catarina y, por extensión, en Brasil está dispersa en varios archivos de instituciones públicas y privadas, una parte importante de la cual definitivamente se pierde. En Santa Catarina, los agrimensores registrados provenían de escuelas en otros estados o con diplomas validados de otros países, una condición que dificulta la recuperación de documentación que apunta al primer profesional capacitado en Santa Catarina. La investigación indica que en 1901, el Instituto Técnico Comercial y Naval surgió en Florianópolis, una escuela con este propósito en Santa Catarina, estableciéndose a partir de allí, otras instituciones que luego comenzaron a formar Agrimensores en el Estado.

Palabras-clave: Instituto Technico Commercial e Naval. Agrimensura. Frederico Selva. 


\section{Introdução}

A história da formação de agrimensores em Santa Catarina e por extensão no Brasil está dispersa em vários arquivos de instituições públicas e privadas, sendo que uma parte significativa dos registros está definitivamente perdida pela falta de cuidado no armazenamento dos materiais ou em razão do descarte de documentos relativos às escolas de formação que não existem mais.

Dos registros que se pode localizar, foram utilizadas fontes primárias disponíveis em arquivos e bibliotecas. Alguns registros fundamentais para a pesquisa foram obtidos junto ao Museu de Topografia Professor Ênio Miguel de Souza e à Biblioteca Professor Lúcio Mendes, ambos mantidos pelo Curso Técnico de Agrimensura do Instituto Federal de Santa Catarina, que mantém entre suas finalidades o resgate da história do ensino, dos profissionais e dos equipamentos utilizados na trajetória dos trabalhos em topografia e agrimensura, especialmente no Estado pesquisado.

O marco temporal para partida das pesquisas considerou a Lei de Terras de 1850 que exigia que as medições de terras públicas fossem realizadas por agrimensores com diplomas reconhecidos e devidamente registrados nos chamados livros dos agrimensores. A citada legislação brasileira apontou para a necessidade, que a partir de então seria crescente, de profissionais que soubessem medir e demarcar o nosso território desde o início da ocupação do país.

Por força do teor da Lei, os primeiros agrimensores que trabalharam em Santa Catarina possuíam diplomas emitidos por escolas de outros estados ou por outros países, validados para exercício no Brasil, condição que, de acordo com as pesquisas realizadas, denota a ausência de escolas de formação no Estado na época.

Com o passar do tempo Santa Catarina passou a dispor de instituições de ensino que pudessem formar profissionais habilitados para o exercício de serviços de medição de terras, e então, por meio dos registros ainda disponíveis, propõe-se identificar qual a primeira escola a diplomar um agrimensor em Santa Catarina e outros pontos da história de formação de Agrimensores no Estado, relacionando os professores envolvidos nas escolas que contribuíram fundamentalmente para formação de profissionais pioneiros deste ofício em Santa Catarina.

\section{Agrimensores em Santa Catarina}

A necessidade de profissionais para atuarem na demarcação das terras no Brasil e em Santa Catarina é notória nas correspondências emitidas pelos governantes da época em função da ocupação desordenada que se realizava em todo território brasileiro.

A este propósito escreveu Taunay (1920 apud Reis Filho, 2000 p.141) “desde 1590, aliás, pedia a Camara insistentemente que se contractasse para a villa dois 'pilotos', 'práticos de agulha', ou agrimensores, por causa das questões de terras".

Além da ausência de escola de formação, as dificuldades na medição em relação a densa vegetação existente à época e o alto custo para a realização dos trabalhos formavam um cenário desfavorável à oferta destes profissionais. Em Santa Catarina já se reclamava da

falta de quem saiba entrar nos mattos a medir, a demarcar terras; para o que se carecia de Geógrafos, ou experientes Engenheiros e na falta de huns, e outros alguns Pilotos que entendendo os rumos a ensinarem a seguir a que ouverem de acomodar, para se não confudirem nas extremas com que devem separar-se. ((ESCUDEIRO, 1750, apud PIAZZA, 1992 p. 383). 
A legislação portuguesa e, posteriormente, a brasileira preocupavam-se em exigir a medição e demarcação das terras tanto particulares quanto as que seriam destinadas às vilas e às províncias, para conseguir este intento seriam necessários agrimensores.

O Alvará de 05 de outubro de 1795 foi uma das providências tomadas pela Coroa Portuguesa para organizar a ocupação do território brasileiro, que segundo Cunha Junior (1998), exigiu a medição e demarcação, proibiu a concessão de sesmarias aos que já tivessem sido beneficiados com concessão anterior, reduziu o limite de áreas das sesmarias para no máximo três léguas, sendo que em algumas capitanias o limite máximo era de uma légua e, em outras, de apenas meia légua.

A Lei de Terras de 1850 com o seu Regulamento, o Decreto $n^{\circ} 1.318 / 1854$, foi um marco da legislação territorial no Brasil destacando o fato de ter sido, na prática, o único momento da história brasileira que se conviveu com um sistema de organização territorial baseado no levantamento da propriedade imobiliária com medições, inclusive designando os procedimentos e os profissionais responsáveis por essa tarefa. O referido Decreto, em seu Artigo 35, definia os profissionais habilitados a trabalharem com medição.

Art 35. Os Agrimensores serão pessoas habilitadas por qualquer Escola nacional, ou estrangeira, reconhecida pelos respectivos Governos, e em que se ensine topographia. Na falta de título competente serão habilitados por exame feito por dous Officiaes do Corpo de Engenheiros, ou por duas pessoas, que tenhão o curso completo da escola Militar, sendo os Examinadores nomeados pelos Presidentes das Provincias (BRASIL,1854).

Um novo Decreto, $\mathrm{n}^{\circ} 3198$, publicado em dezembro de 1863 para regulamentar a nomeação de profissionais para exercerem a função de agrimensores estabelecia:

Approva as instrucções para nomeação de Agrimensores. Instrucções para nomeação de Agrimensores

Art. $1^{\mathrm{o}}$ Sómente poderão ser empregados, como Agrimensores, nas medições de terras publicas e particulares, feitas por ordem ou com participação do Governo:

$1^{\circ}$ Os engenheiros geographos com carta passada pelas escolas nacionais;

$2^{\circ}$ Os habilitados com carta de curso completo da Academia ou Escola de Marinha da Côrte;

$3^{\circ}$ Os pilotos de carta pela mesma Escola ou Academia, ou por ellas reconhecida;

$4^{\circ}$ Os Agrimensores habilitados com titulo na fórma destas instrucções; $5^{\circ}$ Os que, como taes, tiverem sido empregados pelo Governo até esta data. (BRASIL, 1863).

Tais regulamentos estavam em vigência até a data de constituição das primeiras escolas de formação de Agrimensores.

\section{Ensino da Agrimensura no século XIX até meados do século XX}

Apesar da demanda latente, durante o século XIX não houve por parte do governo da Província de Santa Catarina, segundo Fonseca (1986), iniciativa de criar uma escola de ofícios. Somente em 1883, a partir de um projeto particular, com apoio do governo da época, foi criado o Liceu de Artes e Ofícios. 
Também por iniciativa particular no final do século XIX, houve uma tentativa de criação de um curso de Agrimensura por parte do Professor Liberato Bittencourt conforme anúncio no Jornal República:

O congresso Representativo de Estado de Santa Catarina decreta: Art. $1^{\circ}$ Será considerado oficial no Estado de Santa Catarina, o titulo de agrimensor outorgado pelo "Colégio Bittencourt" a seus alunos aprovados em todo o curso de agrimensura, em exames fiscalizados pelo governo do Estado. 20 de setembro de 1897 (JORNAL A REPUBLICA, 1897, p.2).

Esta tentativa de criação de um colégio para o ensino de agrimensura, que também seria utilizado para a instrução primária e secundária, não prosperou. Não foram registrados profissionais formados pela instituição devido ao pouco tempo que se manteve em atividade.

Frente aos relatos, o cenário na cidade de Desterro, atual Florianópolis, em 1900 (Figura 1), era de poucos avanços na educação, contando apenas com três unidades de ensino, restringindo-se à Escola Normal, ao Gymnasio Catharinense e o Lyceu de Artes e Oficios, estabelecimentos para atender uma população de 32.814 habitantes, tendo o Estado de Santa Catarina, na mesma época 320.289 habitantes, segundo dados do Instituto Brasileiro de Geografia e Estatística (2020).

Figura 1 - Vista do centro de Florianópolis em 1900.

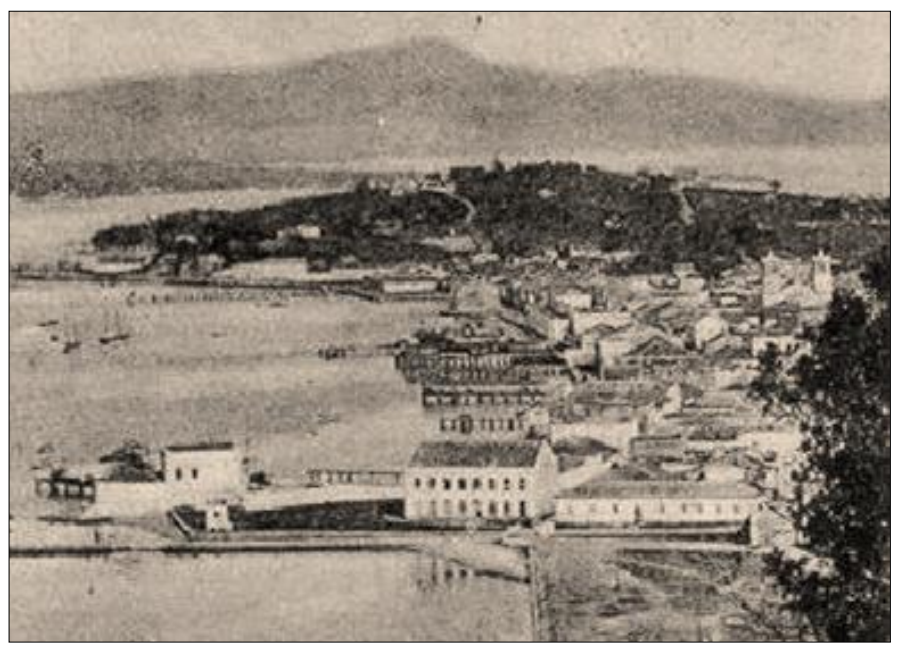

Fonte: Velho Bruxo. Disponível em: http://www.velhobruxo.tns.ufsc.br/FotoAntigas/Album006/pages/6081\%20-

\%20Cidade\%20vista\%20do\%20morro\%20da\%20Prainha\%20-20antes\%20da\%20ponte\%20H_L\%20provavel\%201900_jpg.htm. Acesso em: 13 jun. 2020

Alguns anos depois da iniciativa infrutífera do Professor Liberato Bittencourt, já em 1901, há registro de anúncios publicados em julho do referido ano nos jornais O Dia e República sobre a criação de uma escola em Florianópolis voltada a formação de profissionais. A iniciativa, mais uma vez particular, desta vez partia de Emílio Blum (Figura 2), Superintendente Municipal (Prefeito) em vários períodos entre 1890 a 1901. 
Figura 2 - Retrato de Emilio Blum.

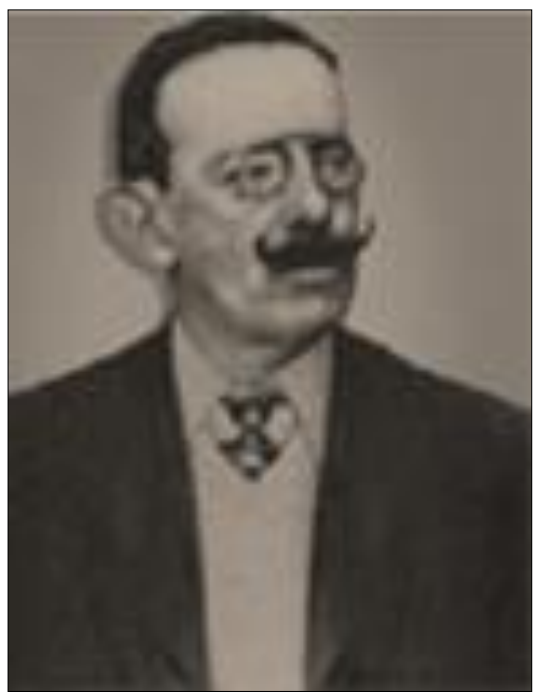

Fonte: Associação Comercial e Industrial de Florianópolis (2015). Disponível em: http://www.acif.org.br/a-acif/galeria-depresidentes/attachment/1915-cel-emilio-blum/. Acesso em: 13 jun. 2020

Nascido em Bagé, no Rio Grande do Sul, se formou engenheiro na Europa e retornou ao Brasil com ideias republicanas. Morou na então Desterro (Atual Florianópolis), onde atuou politicamente pelo Estado com uma bem-sucedida articulação entre os poderes executivo e legislativo para aprovarem legislações que possibilitassem o funcionamento da instituição de ensino, então chamada Instituto Technico Commercial e Naval.

Emilio Blum foi ainda Deputado Estadual Constituinte e Deputado Federal, lutou pelas causas legalistas, recebendo por isto a patente de Coronel. Outro movimento em que esteve envolvido foi a criação da Associação Comercial de Florianópolis, tendo sido seu primeiro Presidente.

Sua dedicação foi decisiva para implantar o Instituto, contando com farta divulgação em jornais de orientação republicana, dos quais se localizou o registro. A instituição teve o propósito inicial de formar pilotos (para navegação marítima) e guarda livros, além de aceitar alunos em disciplinas isoladas voltadas à preparação para exames em Faculdades da República, bem como alunos para aulas de piano e música. Depois dos primeiros anúncios sobre o início das atividades do estabelecimento escolar, foram acrescentados, aos inicialmente previstos, os cursos de Fazenda, para aqueles que desejassem trabalhar em alfândegas, e o de Agrimensura.

Com oferta para então quatro cursos, a instituição de ensino, no Artigo $1^{\circ}$ de seu estatuto destacou que, com o propósito de "preencher uma lacuna bastante sensível, destina-se ao preparo da mocidade para quatro importantes carreiras: a Commercial, a de Pilotagem, a de Agrimensores e a de Fazenda." (INSTITUTO TECHNICO, 1901, p.1). No mesmo Artigo, o Parágrafo único especificava:

Para esse fim o Instituto manterá quatro cursos; o Commercial, destinado aos que se dedicarem a essa profissão, assegurando-lhes o diploma de Guarda-livros jurisperito; o de Pilotagem, que facultará aos que concluirem o titulo de Piloto de 1a e 2 a classe; o de Agrimensura, que assegurará aos que terminarem o curso o diploma de Agrimensor e o de Fazenda, destinado a ministrar aos que seguirem essa profissão os conhecimentos exigidos para os Concursos (INSTITUTO TECHNICO, 1901, p.1). 
O Instituto foi inaugurado a 15 de julho de 1901 e saudado pelo jornal O Dia "dispondo de um corpo docente habilitado e trabalhador, o Instituto poderá dar os fructos que d'elle todos esperam" (JORNAL O DIA,1901, p.3).

Um mês após a inauguração, o Governador do estado Felippe Schmidt sancionou a Lei 502, de 16 de agosto de 1901, reconhecendo a titulação atribuída pelo Instituto:

Considera official, no Estado, o título de Agrimensor ou de Guarda-livros jurisperito, outorgado pelo Instituto Techinico Commercial e Naval.

O Tenente-Coronel Felippe Schmidt, Governador do Estado de Santa Catharina.

Faço saber a todos os habitantes deste Estado que o Congresso Representativo decreta e eu sanciono a Lei seguinte:

Art. $1^{\circ}$. Será considerado oficial, no Estado de Santa Catharina, o titulo de Agrimensor ou de Guarda-livros, jurisperito, outorgado pelo Instituto Technico Commercial e Naval a seus alumnos approvados nos respectivos cursos em exames realisados pelo governo do Estado.

Art. $2^{\circ}$. Revogam-se as disposições em contrario. (SANTA CATARINA, 1901).

Sendo de iniciativa privada, eram cobradas taxas para formalizar a matrícula, realizar exames e emitir diplomas. Também eram cobrados valores mensais ou trimestrais para os cursos e mensalidades para matérias isoladas.

O Instituto, pelos registros, não possuía instalação própria, funcionando na sede da Escola Normal (Figura 3), localizada na atual esquina das ruas Trajano com Tenente Silveira, no período noturno entre as seis e nove horas. A própria residência de Emilio Blum foi usada como secretaria, de acordo com relatos encontrados.

Figura 3 - Edifício da Escola Normal

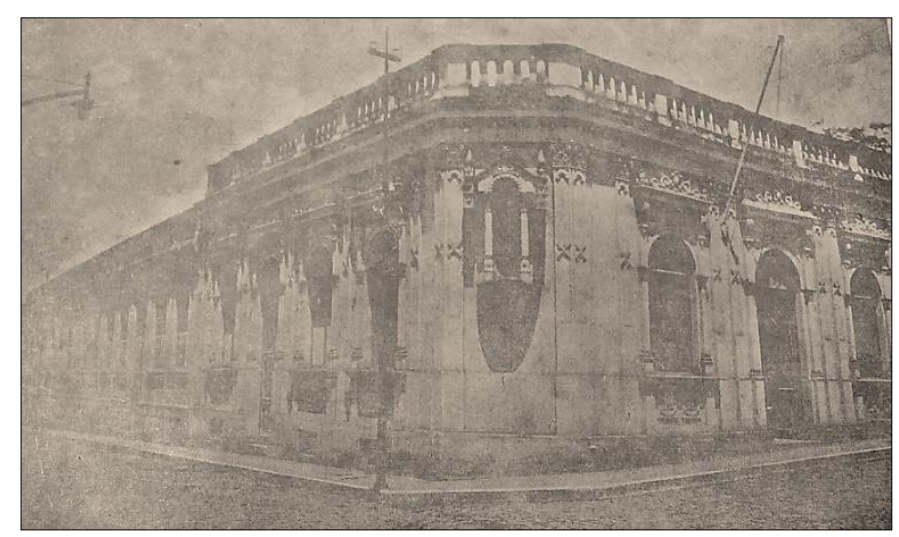

Fonte: Jornal A Phenix, nº 26 (1916).

Dois anúncios referentes às atividades do Instituto demonstram o quanto se desejava o sucesso do empreendimento, o primeiro dava conta de uma subvenção do Estado para a manutenção de alunos, que nunca foi utilizada. O segundo sobre a possível construção de um pensionato para alunos do interior, iniciativa também não concretizada.

Os estatutos do Instituto previam a possibilidade de oferecer, mediante requerimento dos interessados, exames para a obtenção de diploma do curso ou de validação de disciplinas isoladas. Para tanto, o Instituto comporia uma banca para a realização das provas, seguindo orientações regulamentadas pelo governo. 
Em novembro de 1902 o Governo do Estado, através do Decreto 173 emitido pelo vicegovernador Tenente Coronel Vidal Ramos, que posteriormente seria Governador do Estado, responsável pela reforma na educação, citando o Instituto como exemplo a ser seguido, formalizou as instruções para a realização de exames finais para os cursos de agrimensores e guarda livros do Instituto. As instruções para a realização das provas previam exames chamados de vagos, no qual o candidato poderia realizar comprovando experiência de trabalho na área por no mínimo 10 anos.

\section{O Curso de Agrimensura do Instituto Technico Commercial e Naval}

Os alunos do então criado Curso de Agrimensura, segundo os estatutos do Instituto, deveriam ser maiores de 16 anos, saber ler e escrever, além comprovarem o conhecimento das quatro operações matemáticas através de diploma de escola ou por meio de exame preliminar.

O curso estava dividido em três séries, sendo que na primeira, chamada de Curso Preparatório, estavam dispensados os alunos que apresentassem diplomas de escolas que pudessem comprovar conhecimento adquirido para os temas que compunham as disciplinas.

A segunda série, chamada Curso Preliminar, estava voltada para o preparo profissional e o aperfeiçoamento teórico dos estudantes. A terceira série chamada de Curso Especial envolvia as disciplinas específicas da área e aulas práticas.

As disciplinas que compunham o Curso de Agrimensura são apresentadas na tabela 1, conforme o estatuto do Instituto Technico Commercial e Naval.

Tabela 1 - Distribuição das disciplinas do curso de Agrimensura.

\begin{tabular}{|c|c|c|}
\hline $\begin{array}{c}\text { 1a Série } \\
\text { (Curso preparatório) }\end{array}$ & $\begin{array}{c}2 \text { Série } \\
\text { (Curso Preliminar) }\end{array}$ & $\begin{array}{c}3 \text { Serie } \\
\text { (Curso Especial) }\end{array}$ \\
\hline $\begin{array}{l}\text { - Portuguez } \\
\text { - Francez } \\
\text { - Inglez ou Allemão } \\
\text { - Mathematicas elementares } \\
\text { (Arithmetica, Algebra até } \\
\text { equações do } 2^{\circ} \text { gráo, } \\
\text { inclusive) } \\
\text { - Geographia e } \\
\text { Cosmographia. } \\
\text { - Historia Geral do Brazil. }\end{array}$ & $\begin{array}{l}\text { - Mathematicas (revisão e } \\
\text { complementos de Arithmetica e } \\
\text { Algebra) } \\
\text { - Geometria e Trigonometria. } \\
\text { - Phisica Experimental } \\
\text { (barologia, acustica e optica.) } \\
\text { - Noções de Sciencias Naturaes. } \\
\text { - Contabilidade, Escripturação } \\
\text { Mercantil. } \\
\text { - Desenho á mão livre e } \\
\text { geométrico (elementar). }\end{array}$ & $\begin{array}{l}\text { - Phisica experimental } \\
\text { (termologia, electrologia e } \\
\text { metereologia) } \\
\text { - Topographia. } \\
\text { - Elementos de Geodesia e de } \\
\text { Astronomia } \\
\text { - Desenho topographico. } \\
\text { - Legislação de terras. } \\
\text { - Exercicios - Levantamento, } \\
\text { Nivelamento. } \\
\text { - Cartas topographicas e } \\
\text { Geodesicas. }\end{array}$ \\
\hline
\end{tabular}

Fonte: Estatuto do Instituto Technico adaptado pelos Autores (2020.

No curso de Agrimensura, tanto pelo estatuto do Instituto quanto pelo decreto 173 do Governo do Estado, que atendia as instruções do decreto 4247 de novembro de 1901 do Governo Federal sobre os exames gerais, os candidatos aptos a receberem o diploma poderiam realizar exames chamados vagos, submetendo-se às provas de Topographia e Geodesia organizadas pela banca examinadora aprovada pelo fiscal do Governo, desde que comprovada experiência de atuação profissional na área.

Entre os professores, chamados lentes, dos cursos do Instituto, estavam inicialmente, além do próprio Emílio Blum, os Deputado do Congresso do Estado, Dr. Campos Mello, o Procurador Geral do Estado Dr. Thiago da Fonseca (professor de Portuguez, Historia e Geographia), o Advogado Dr. Manoel Adeodato de Souza Junior, Tenente da Armada Affonso Livramento e o Professor Paulo Scheefler. Este número poderia aumentar conforme a demanda em função do número de alunos. 
Estes professores formavam a chamada congregação, que tinha a responsabilidade de elaborar material didático, os horários das aulas, o ementário das disciplinas e por fim elaborar e compor a banca dos exames de final de ano.

\section{O primeiro agrimensor formado}

Dentre os alunos matriculados na instituição destaca-se Frederico Selva (Figura 4), imigrante chegado ao Brasil, que entre 1901 e 1902, período em que o Instituto esteve em atividade, trabalhava em Florianópolis prestando serviços de topografia para a prefeitura municipal.

Figura 4 - Frederico Selva

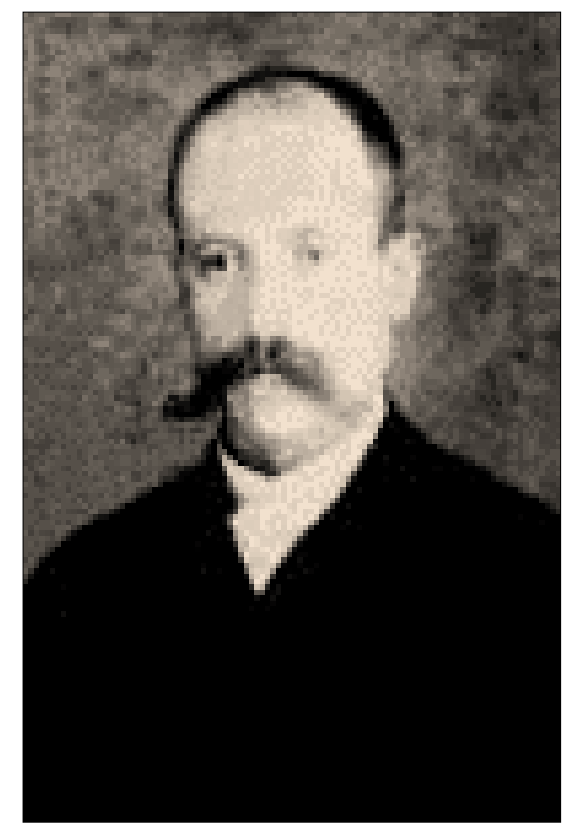

Fonte: Família Selva. Disponível em: http://www.familiaselva.com.br/index.php?modulo=album. Acesso em: 13 jun. 2020

Dentre as demandas de trabalho estavam levantamento e retificação das principais ruas do centro da cidade, além de elaboração de plantas com arruamento e benfeitorias que contaram com seus conhecimentos de desenhista, habilidade adquirida quando trabalhou para a Companhia Metropolitana, contratada para a implantação das colônias de imigrantes italianos no sul de Santa Catarina.

Com experiência e atuação destacada em vários projetos de desenvolvimento do Estado, na região carbonífera e na comissão de melhoramento no Porto de Laguna, o republicano ferrenho, matriculado no Instituto, solicitou a realização do exame chamado vago.

Em 4 de dezembro de 1902, conforme registros, mediante banca composta pelos professores do Instituto Technico: Emilio Blum, Carlos Wendhausen, Thiago Fonseca, Fausto de Souza e Fernando Machado, Frederico Selva realizou o exame das disciplinas necessárias para a sua diplomação no curso de Agrimensura do referido Instituto.

No dia seguinte, 5 de dezembro de 1902, Frederico Selva, em solenidade presidida pelo Vice-governador Vidal Ramos, nos salões do Lyceu de Artes e Ofícios, contando com a presença do Prefeito de Florianópolis Coronel Pereira Oliveira, com o Diretor, professores e alunos do Instituto, alunos da Escola Normal e do Gymnasio, além de outras personalidades do Estado como José Boiteux e Fernando Machado, Frederico Selva foi diplomado Agrimensor (JORNAL A REPÚBLICA, 1902).

Em 12 de dezembro do mesmo ano de 1902, no último ato publicado do Instituto Technico Commercial e Naval que se têm conhecimento antes do encerramento de suas 
atividades, consta a inscrição no Livro dos Agrimensores do diploma de Frederico Selva, lhe conferindo direitos para atuar como Agrimensor em terras públicas.

No Livro de Registro dos Títulos de Agrimensores de Santa Catarina, aberto em 1864, consta nos registros de 1902, a inscrição do diploma de Frederico Selva, com transcrição paleográfica dos autores:

Estados Unidos do Brazil. = Estado de Santa Catharina. = Instituto Technico Commercial e Naval. Diploma. = Eu Emilio Blum, Director do Instituto Technico Commercial e Naval do Estado de Santa Catharina, usando das attribuições que me são conferidas pelo regulamento em vigor, e tendo em consideração as provas apresentadas nos exames a que se submetteu, em 4 e 5 do corrente ano o Señ Frederico Selva, filho de Constantino Selva, nascido na Itália e brasileiro naturalisado, com 39 annos de idade, mandei passar este diploma de Agrimensor com os direitos outorgados pela Lei $\mathrm{n}^{\circ}$ 502, de 16 de Agosto de 1901. (ARQUIVO PÚBLICO DO ESTADO DE SANTA CATARINA, 1902).

É provável que Frederico Selva tenha sido o único candidato a ser inscrito na modalidade de exame vago e ser o único aluno a receber a diplomação.

Com o fim do Instituto Technico no final de 1902, somente em 1910 seria inaugurada uma escola profissional em Santa Catarina a Escola de Aprendizes Artífices atual Instituto Federal de Santa Catarina.

\section{Frederico Selva e a criação de um curso superior no Estado.}

Florianópolis não contava com nenhum curso de ensino superior até 1917, a formação de profissionais na capital era limitada e fazer um curso superior fora de Florianópolis era somente para os ricos ou para quem conseguisse alguém para financiá-lo (VIEIRA, 1986).

As primeiras tentativas de criar um estabelecimento de nível superior datam do início do século XX. A instituição pioneira no Estado de Santa Catarina, o Instituto Politécnico surgiu em 1917 tento a frente da iniciativa José Arthur Boiteux e conforme noticiado nos jornais que circulavam em Florianópolis na época.

Dentre os cursos superiores oferecidos pelo Instituto Politécnico de Florianópolis, destaca-se o de Agrimensura, sendo o primeiro curso da área de Engenharia do Estado, que iniciou suas atividades no ano de fundação da instituição, 1917, perdurando o ensino até sua extinção, em 1934. Quando da concepção do Instituto Politécnico, o nome ligado à organização do curso superior voltado à Agrimensura na instituição foi o de Frederico Selva, agrimensor formado pelo Instituto Technico que anos depois atuou como Diretor Interino do Instituto Politécnico.

O ensino médio profissional começou sua consolidação a partir da metade do século XX conforme afirma Dallabrida (2007), sendo que até 1950 existia um fosso entre o ensino secundário e o profissionalizante, o primeiro para as elites e o segundo considerado de segunda classe.

Em 1962 na então denominada Escola Industrial de Florianópolis, iniciam-se os dois primeiros cursos técnicos de nível médio e em 1966 já com a denominação de Escola Industrial Federal de Santa Catarina, tendo à frente o Professor Georges Wildi, cria-se o Curso Técnico de Agrimensura, inicialmente com 277 alunos. As primeiras turmas tiveram professores Sezefredo Blascke, Salvador Poeta e Carlos Büchele Junior, formados no Instituto Politécnico de Florianópolis. 


\section{Discussão}

A educação profissional teve início em Santa Catarina por iniciativas particulares com o apoio do Governo estadual principalmente em termos de legislação. Os registros sobre a existência de escolas estaduais profissionais constam somente após a metade do século XX.

A criação de escolas em Florianópolis era uma preocupação desde o Império, porém com a República, apesar do acelerado processo de desenvolvimento da capital e do estado de Santa Catarina, a educação ficou relegada ao segundo plano, obrigando os catarinenses a estudarem em outros estados.

A necessidade de formação de Agrimensores, assim como no passado, continua a ser uma exigência da sociedade que precisa ter a certeza que os limites de suas propriedades estejam corretamente determinados.

A criação do Instituto Technico Commercial e Naval por iniciativa de Emilio Blum, embora com uma existência pequena, foi a semente do ensino profissional em Santa Catarina, em particular na área de Infraestrutura com o Curso de Agrimensura. Frederico Selva primeiro e único diplomado, juntamente com José Boiteux (presente em sua diplomação) criaram o Instituto Polithecnico e os primeiros Cursos superiores de Santa Catarina.

Outro aspecto a ser destacado sobre o Instiutto Technico é a previsão, em seu estatuto e posteriormente na Lei estadual, da possibilidade de reconhecimento da experiência profissional como requisito mediante exames para a obtenção de título profissional. Esta modalidade hoje é chamada de certificação de competências e vem sendo adotada pelo Curso Técnico em Agrimensura do Instituto Federal de Santa Catarina.

Alguns dos formandos no Instituto Polithecnico foram Professores das primeiras turmas do Curso Técnico em Agrimensura da Escola Industrial de Santa Catarina, formando vários elos desta corrente de Agrimensores formados no Estado.

A curiosa história do Instituto é contada através dos anúncios em jornais e de uns poucos documentos esparsos em arquivos do Estado, tentando passar sempre uma mensagem de otimismo em relação a escola.

A pesquisa, envolveu o levantamento bibliográfico sobre o tema Instituto Technico Commercial e Naval, e teve início a partir da consulta a um dos livros de 1982, de autoria dos Professores José Edu Rosa e Ademar Américo Madeira, exemplar da Biblioteca Professor Lucio Mendes do Curso Técnico de Agrimensura, que possuí um acervo de livros sobre a história do ensino no Brasil.

Considerada documental, a pesquisa foi elaborada a partir de materiais que não receberam tratamento analítico, baseada em material impresso antigos, como jornais da época e documentos produzidos pelo Instituto Technico, e por este motivo, o primeiro local visitado para iniciar a busca por materiais foi o setor de obras raras da Biblioteca Pública do Estado de Santa Catarina, consultando na Hemeroteca os jornais dos anos de 1900 e 1902, tendo encontrado referências nos jornais O Dia e República.

Também no setor de obras raras foi encontrado o Estatuto do Instituto Technico Commercial e Naval, obra esta que agora se encontra disponível na Hemeroteca digital da Biblioteca do Estado, digitalizada à pedido.

Foram consultados ainda o setor de obras raras da Biblioteca da Universidade Federal de Santa Catarina, o Arquivo Público Municipal, a Biblioteca da Universidade Estadual e o Arquivo Público Estadual.

No arquivo Público do Estado foram encontrados documentos referentes ao Instituto e do seu fundador que comprovaram a existência da instituição, mas, principalmente um importante documento para História da Agrimensura em Santa Catarina.

Este documento está catalogado como o Livro dos Agrimensores, trata-se da primeira forma de registro profissional, nele consta o nome dos profissionais e a instituição de ensino na 
qual o mesmo se formou ou validou seu diploma.

Outra importante fonte de pesquisa foi a Hemeroteca Digital da Biblioteca Nacional onde foram consultados os jornais digitalizados do acervo de Santa Catarina entre os anos de 1890 e 1910.

Estes e outros documentos históricos possuem grande relevância visto que as fontes estão na origem, constituem o ponto de partida, a base, o ponto de apoio da construção historiográfica que é a construção, no plano do conhecimento, do objeto histórico estudado. (Saviani, 2004, p.6). Para o autor, as origens enquanto registro, enquanto testemunhos dos atos históricos são a fonte do nosso conhecimento histórico, isto é, é delas que brota, é nelas que se apoia o conhecimento que produzimos a respeito da história.

Toda documentação encontrada foi fotografada ou digitalizada com consentimento de seus detentores e fará parte do acervo digital da Biblioteca e do Museu do Curso Técnico em Agrimensura.

\section{Considerações finais}

O presente estudo teve por motivação pesquisar qual a primeira escola a diplomar um agrimensor, tendo sido realizadas para este fim, pesquisas em fontes primárias disponíveis em arquivos e bibliotecas e pesquisas em acervo bibliográfico.

Foram encontrados registros sobre a história da formação de Agrimensores em Santa Catarina e as ligações entre os nomes envolvidos nas escolas que formaram estes profissionais, destacando-se a figura de Frederico Selva, o primeiro agrimensor formado na primeira escola de Agrimensura do estado, o Instituto Technico Commercial e Naval, que posteriormente contribuiu com a criação do Instituto Polithecnico, primeira instituição de ensino superior no Estado de Santa Catarina.

A partir da pesquisa realizada, o Curso Técnico de Agrimensura do Instituto Federal de Santa Catarina, através de seu Museu de Topografia, Professor Ênio Miguel de Souza, e de sua Biblioteca, Professor Lucio Mendes, armazenará em seu acervo, as referências bibliográficas primárias encontradas em meio digital para que possa contribuir com a preservação de arquivos e documentos que contam a História da Agrimensura.

\section{Referências}

ARQUIVO PÚBLICO DE SANTA CATARINA. Livro dos Agrimensores. Florianópolis, 1864

BRASIL. Decreto-lei $n^{\circ} 1.318$, de 30 de janeiro de 1854. Manda executar a Lei N. ${ }^{\circ} 601$ de 18 de Setembro de 1850. Disponível em: http://www2.camara.leg.br/legin/fed/decret/18241899/decreto-1318-30-janeiro-1854-558514-publicacaooriginal-79850-pe.html. Acesso em 12 jul. 2020.

BRASIL. Decreto-lei n ${ }^{\circ} 3.198$, de 16 de dezembro de 1863. Approva as instrucções para nomeação de Agrimensores. Disponível em: http://www2.camara.leg.br/legin/fed/decret/ 1824-1899/decreto3198-16-dezembro-1863-555382-publicacaooriginal-74601-pe.html. Acesso em 12 jul.2020.

CONGRESSO. Jornal Republica, Florianópolis, 28 SET.1897. p.2.

CUNHA JUNIOR, Dirley. Terras devolutas nas constituições republicanas. Revista Jurídica dos formandos em direito da UFBA, Salvador, s/e., v. IV, pp. 261-276, jul./dez. 1998. 
DALLABRIDA, Norberto. O ginásio das elites dirigentes. In: DALLABRIDA, Norberto; CARMINATI, Celso João. (Org.). O tempo dos ginásios: ensino secundário em Santa Catarina (final do século XIX-meados do século XX). Campinas - SP: Mercado de Letras, 2007, p. 261-285.

FONSECA, Celso Suckow da. História do ensino industrial no Brasil. Rio de Janeiro: SENAI/DN/DPEA, 1986. 5V. 319 p.

INSTITUTO BRASILEIRO DE GEOGRAFIA E ESTATÍSTICA, IBGE Estatísticas do Séc. XX. Disponível em: https://seculoxx.ibge.gov.br/populacionais-sociais-politicas-e-culturais/ busca-por-temas/populacao.html. Acesso em 10 jul. 2020.

INSTITUTO TECHNICO. Jornal Republica, Florianópolis, 20 set. 1897. p.2.

INSTITUTO TECHNICO. Jornal Republica, Florianópolis, 7 dez.1902. p.1.

INSTITUTO TECHNICO COMMERCIAL E NAVAL. Estatuto, Florianópolis, 1901. 13p.

INSTITUTO TECHNICO COMMERCIAL E NAVAL. Jornal O Dia, Florianópolis, 11 jul.1901. p.3.

JORNAL PHENIX, anno I, número 26. Capa, Florianópolis,1916

PIAZZA, Walter Fernando. A epopéia açórico - madeirense 1747- 1756. Florianópolis: UFSC/ Lunardelli, 1992.490 p.

REIS FILHO, Nestor Goulart. Evolução urbana do Brasil (1500-1720). São Paulo. Pioneira. 1968. 235p.

ROSA, Jose Edu; MADEIRA, Ademar Américo. Odontologia Catarinense: evolução, ensino e movimento associativo. Florianópolis: Ed. da UFSC; [S.I]:Lunardelli, 1982. 333p

SANTA CATARINA. Lei Estadual n ${ }^{\circ} 502$ de 16 de agosto de 1901, reconhece a titulação atribuída pelo Instituto Technico Commercial e Naval.

VIEIRA, Amalize de Hollanda. Instituto Polytechnico: no contexto sócio-cultural de Florianópolis. Florianópolis: A\&P, 1986. 128p. 